\title{
La economía política del ajuste estructural
}

\author{
Wim Pelupessy
}

\section{Introducelón}

"Es diffcil definir para el gobierno un plan de desarrollo, por eso se dedica a disenar planes operativos. de un ano, que son más bien operaciones u operaciones de apaga fuego", declaró Alberto Benítez Bonilla al despedirse de la presidencia del Banco Central de Reserva de El Salvador (La Prensa Gráfica, 12 de mayo de 1987).

El propósito de este artículo es, analizar como la política-económica de los anos 80 se encuentra influenciada básicamente por dos modelos económicos diferentes que no siempre coinciden en cuanto a las medidas concretas a tomar, ni tampoco en sus efectos a las principales variables macro-económicas y sociales. El primer modelo, es el de las reformas estructurales introducido en el ano 1980 con la ayuda directa del Gobiemo de los Estados Unidos relacionado estrechamente con la estrategia global de contrainsurgencia y cuya base de apoyo debe buscarse en las filas del Partido Demócrata Cristiano (PDC) de El Salvador y algunos partidos menores, una fracción de las fuerzas armadas y el ala reformista del movimiento popular.

El otro modelo es el del ajuste productivo, impulsado por los organismos financieros internacionales como el Fondo Monetario Internaclonal (FMI) y el Banco Mundial, que lo proponen a los Gobiernos de América Central como estrategia para solucionar la crisis económica generalizada en la región a partir de la finalización de la década de los 70.

El modelo de las reformas puede ser considerado como basado 
principalmente en la dinamización del mercado interno y la extensión de la base social de apoyo al gobierno, con una amplia intervención estatal. Contrariamente, el ajuste busca sobre todo la reactivación de la economía basada en los mercados externos, aumentando la oferta de bienes exportables, fortaleciendo el sector privado con un papel restringido del Estado. Dada la particular estructura productiva y conformación de clases en El Salvador, es la oligarquía con sus asociaciones gremiales, sus partidos políticos de la derecha, apoyado por una fracción de las fuerzas armadas y la tecnocracia, que se ha pronunciado a favor del último modelo. Son estas dos grandes vertientes, las que han afectado la política económica del país, con pesos cambiantes según la coyuntura y la correlación de fuerzas imperantes.

Con el anuncio en enero 1986 por el Presidente Napoleón Duarte, de un conjunto de medidas económicas tendiente a fortalecer el sector productivo privado, y de paquetes de medidas posteriores, parece que el gobierno se habia inclinado más hacia una política de ajuste a pesar de las intenciones reformistas del pasado.

Serán muy limitados los efectos de la anunciada implementación de la segunda fase de la Reforma Agraria y de la aprobación de la 'Ley de Transferencia Voluntaria de Tierras' a fines de 1988. Hay que tomar en cuenta que la nueva constitución de 1983 ha declarado como Inafectables todas las propiedades menores de $\mathbf{2 4 5}$ ha, dejando solamente el $3 \%$ del área de cultivo del país como potencialmente afectable. Son mucho más importantes las recientes leyes de incentivos a la producción y la productividad, de fomento al algodón, la caficultura y el desarrollo ganadero, de la reducción de las tasas de interés, del impuesto sobre la renta y de garantía a la inversión extranjera.

En las partes siguientes del presente trabajo se analizan las causas de este cambio y se proporcionan algunos argumentos para evaluar la viabilidad de la nueva política económica, en los cuales se considera también el contexto sociopolítico.

\section{La nueva politica económica}

La introducción de las reformas estructurales en el agro, la banca y la comercialización externa e interna a comienzos de la presente década, representa una ruptura con la política económica de la época de posguerra y sobre todo con el papel del Estado en ésta. La política económica hasta 1980 cumplió sobre todo el papel de condicionante de los grandes cambios económicos, llevados a cabo por el sector privado nacional y extranjero. Los procesos de diversificación agroexportadora con los nuevos cultivos de algodón y de cana de azúcar y la indus- 
trialización mediante el Mercado Común Centroamericano (MCCA), posibilitaron el crecimiento y la modemización casi continua de la economía salvadorena. En el cuadro 1 del anexo se presentan las tasas promedios de crecirniento para los anos 60 y 70 de los sectores económicos, manifestándose valores positivos para todos, tanto los productivos como no productivos. ${ }^{1}$ La fuerte caída de las tasas de la Industria, del comercio y la banca demuestra el agotamiento del proceso de industrialización a fines de la década de los 70 . El carácter no complementario de las estructuras productivas de los países centroamericanos, el tamano restringido de los mercados internos y las contradicciones entre las respectivas oligarquias se encuentran entre los más importantes factores limitantes del desarrollo del MCCA. (Bor0es, 1986). Las exportaciones de los productos agricolas tradicionales mantuvieron su papel determinante en el crecimiento. La composición sectorial del PIB cambiaba solamente muy lentamente, tal como lo demuestran los datos correspondientes del cuadro 2 del anexo. En la estructura productiva participa el sector agropecuario con aproximadamente la cuarta parte, la industria manufacturera y la construcción con la quinta parte y los sectores terciarios con un poco más que la mitad del producto bruto.

La política económica podía hacerse cargo con relativa facilidad de los reducidos $e$ incidentales desequilibrios en los balances macroeconómicos, como la cuenta corriente de la balanza de pagos, el déficit fiscal y la inflación que no sobrepasaba el $10 \%$ anual. (Véase la información correspondiente en el cuadro 2). Las condiciones favorables de los mercados mundiales, mejoras en los términos de intercambio, inversiones extranjeras y posteriormente los limitados préstamos externos, garantizaron la existencia de reservas internacionales a niveles de tres meses de importaciones o más ${ }^{2}$. Los préstamos del Fondo Monetario salieron generalmente de los tramos sin condiciones o fueron montos pequenos con una ligera condicionalidad. Con crecientes niveles de exportaciones y gastos públicos alrededor del $10 \%$ del producto bruto intemo, se podía mantener fijo el tipo de cambio del colón a 2.50 por dollar por un periodo prolongado.

Sin embargo, el crecimiento no podía soslayar el creciente proceso de concentración de la riqueza y desigual distribución del ingreso en la economía, el aumento de las familias sin tierra y semiproletarias en el campo, el creciente desempleo y subempleo, que en resumidas cuentas implicaría la imposibilidad, de sectores cada vez mayores de la población, para reproducir su fuerza de trabajo (Pelupessy, 1987: 6365). La política económica mayormente no se preocupó por este tipo de desbalances en la economia, a pesar de los planes y plantea- 
mientos oficiales al respecto (por ejemplo en CONAPLAN, 1972).

En la década del 70 se empeoraron las condiciones de vida y de trabajo de los trabajadores rurales y de la ciudad, manifestándose solamente algún mejoramiento para los trabajadores de los principales núcleos de acumulación, que son los beneficios agroindustriales del café, algodón y azúcar. Esta evolución y el fuerte aumento en las importaciones de materia prima, bienes intermedios y de capital importados, restringieron el desarrollo del mercado interno del país. La consecuencia fue el surgimiento del movimiento popular que cada día cobró mayor importancia y que desemboco en la guerra civil de los ochenta.

Con el inicio de la recesión en los mercados externos a partir de 1974 y la creciente convulsión política en la región, se redujeron las inversiones privadas nacionales y extranjeras y se inició un proceso de fuga de capitales al exterior. Las estimaciones de la fuga en El Salvador varian entre 300 y 700 millones de dólares en el periodo 19771984 , o del $30 \%$ al $70 \%$ del valor acumulado de los déficits de la balanza comercial de este período (Banco Centroamericano, 1987).

El Estado intentó contrarrestar esta tendencia con aumentos en las inversiones públicas, financiándolas externamente, inicialmente sin cambiar su tradicional política de no-intervención en los sectores productivos y manteniendo la misma base tributaria (cuadro 2). Los aumentos de las tasas de interés internacionales y de los precios del petróleo en 1979, aúnados a la contracción de los créditos de proveedores, agravaron la situación de la balanza de pagos y del fisco. De manera que fue necesaria una intervención profunda por parte del Estado en amplias esferas productivas, comerciales y financieras, para poder afectar drásticamente la generación y distribución del excedente generado. Se hizo necesario la introducción de las reformas tanto bajo el punto de vista del nuevo modelo sociopolítico de contrarevolución, como de la base estructural de una política económica dirigida en un grado mayor que la del pasado, hacia el desarrollo de mercado interno. En este modelo, que posteriormente se denomina "modelo de economía social de mercado", el Estado debe cumplir un papel fundamental en la orientación de los sectores pluralistas de producción. La formulación más o menos acabada del modelo, se publicó en el ano 1985, a pesar de haber puesto en práctica a la mayor brevedad posible las reformas.

Como discutimos después en este trabajo, la ayuda económica, política y militar de los Estados Unidos ha sido uno de los principales sustentos al nuevo modelo. Sin embargo, las medidas concretas imple- 
mentadas inmediatamente después de la introducción de las reformas, contienen muchos elementos con efectos parecidos al modelo de ajuste económico de las instituciones financieras. Por lo tanto, es necesario confrontar el modelo reformista con el de los paquetes de polfticas de ajuste que normalmente proponen estas instituciones a los Gobiemos de América Central y sobre todo, con su versión salvadorena formulada por la Fundación Salvadorena para el Desarrollo Económico y Social (FUSADES).

\section{Presentación de los dos modelos}

El modelo de economía social del mercado fue presentado el 27 de ceptiembre de 1985 por Fidel Chávez Mena, Ministro de Planificación, como parte del plan general del Gobierno demócrata cristiano denominado 'El Camino hacia la Paz' (MIPLAN, 1985: 74-133). modelo tiene como postulado central el funcionamiento del mercado, garantizado y a la vez orientado por el Estado en función de la satisfacción de las necesidades básicas de toda la población. La validez de la "teorla del rebalse" (trickling down) es cuestionada, lo cual conlleva a la necesidad de aplicar las medidas económicas y sociales conjuntamente. Las reformas estructurales forman la base del modelo que debe ser completado con nuevas políticas para superar los obstáculos internos y externos a la distribución generalizada de los beneficios del crecimiento económico.

"En este sentido la polltica económica buscará:

- Dar especial énfasis a la producción destinada al consumo de la mayorla de la población

- Orientar los estimulos a la producción de bienes tradicionales para la expansión de las exportaciones y a una mayor diversificacón de su aprovechamiento interno.

- Promover la producción que se oriente a sustituir importaciones, procurando recurrir al uso intensivo de recursos nacionales que eliminen al máximo la dependencia en el exterior". (MIPLAN, 1985: 109).

El estimulo que se quiere dar al desarrollo del mercado interno ocupa el lugar central en esta politica. En el fomento del sector productivo se otorga el rol preponderante a las diversas formas de propiedad del sector privado, especialmente la pequeha y mediana empresa y el sector informal. El plan compromete una amplia gama de medidas de apoyo a estos sectores, en créditos, capacitación, organización, ayuda técnica, etc. 
Mediante la política de inversión se estimulan las inversiones con una tecnologia intensiva en mano de obra y las que hacen mayor uso de la capacidad instalada. El Estado debe participar directamente en la inversión para proyectos, especialmente en el agro.

El modelo propone una política explicita de aumento del consumo privado, garantizando el ingreso real a los consumidores, especialmente los de limitados recursos. Se utilizan para ésto dos mecanismos, que son la flexibilización de los salarios nominales y el control de la inflación mediante controles de precios en los casos necesarios. Además, el Estado garantiza el cumplimiento de compensaciones sociales minimas.

Con la política monetaria y crediticia se quiere proporcionar la liquidez necesaria para la expansión económica, procurando que no se alimente la inflación, ni el déficit en la balanza de pagos. Los flujos financieros tendrán como destino tanto el sector privado como público. Los criterios para una preferencia crediticia al sector privado son la generación del empleo, uso de materia prima nacional, formación de capital fijo, producción de bienes de consumo esenciales, sustitución de importaciones y exportaciones con grandes ingresos netos de divisas. Las actividades del sector público deben ser financiadas, de preferencia, con ingresos corrientes y fondos de ayuda externa. Sin embargo, "durante algún tiempo" sigue el financiamiento por el sistema bancario y en particular el Banco Central.

Con la política fiscal se pretende reducir el déficit fiscal a montos manejables, racionalizando el gasto, sin afectar las prestaciones de servicios básicos, ampliando la base tributaria de una manera redistributiva y "recurriendo lo menos posible a la emisión monetaria" (MPLAN, 1985: 115). Se crea un presupuesto especial para financiar la guerra a través de impuestos temporales, cuyos gastos se distribuyen más equitativamente.

En la política del sector extemo se adecúa la tasa de cambio a niveles reales. Se mantiene el INCAFE para las exportaciones del café, el desestimulo de importaciones no-necesarias y la introducción del nuevo Arancel Común Centro-americano. Los préstamos externos se orientan únicamente a proyectos de inversión.

"La necesidad de un nuevo modelo económico para El Salvador" fue publicado por FUSADES, una entidad privada financiada por la AID, casi a la misma fecha que salió a la luz el modelo económico del gobierno (FUSADES, 1985). Este modelo se fundamenta en un crecimiento hacia afuera, para 10 cual se intenta aumentar continuamente las 
oxportaciones de bienes agricolas e industriales intensivos en mano de obra, aprovechando de esta manera las ventajas comparativas que llene el pals. Una de las características básicas del modelo es que la coordinación de las decisiones de producción y de consumo se realiza oxclusivamente en el mercado que debe guiar también la política económica. El papel del sector público queda relegado básicamente a crear condiciones propicias para el desarrollo del sector privado. No se hace mención explícita de las reformas implementadas, mientras que on algunos casos se puede deducir cierto rechazo a éstas.

Para facilitar la comparación con el modelo anterior se mantiene más o menos el mismo orden de los aspectos considerados en la presentación de las políticas económicas propuestas (para el mediano plazo). Esta política busca principalmente la estabilización de bienes y servicios exportables y por otra parte, el ajuste y la liberalización, "eliminando de manera gradual y progresiva los controles en los aspectos cambiarios, salariales, crediticios y de precios" (FUSADES, 1985: 42).

En cuanto a la política de inversión se propone mejorar la canalización de recursos intemos y externos hacia actividades productivas con inversiones de rapida recuperación (donde existe capacidad ociosa o el caso de la pequena y mediana empresa) o a exportaciones notradicionales. Cuando se obtienen recursos externos podria pensarse en financiar proyectos de exportación con tasas de interés preferenciales. El Estado debe reducir su participación en las actividades rentables (¿Caso de la banca nacionalizada?) y debe orientarse a inversiones en obras de infraestructura de apoyo al sector productivo, sobre todo para el mercado externo, financiado con recursos externos si fuera posible.

El modelo no presenta políticas para garantizar los niveles de consumo, de salarios, o de ingreso minimo de los sectores poblacionales, ni de compensaciones sociales. Más bien, se quiere desestimular el consumo comiente para aumentar el ahorro nacional. Se recomienda que la retribución al trabajador sea congruente con el aumento de su productividad y que se mantengan los programas de seguridad social en la medida que los recursos lo permitan. La polftica monetaria y crediticia deben seguir el crecimiento real de la economla. La distribución del crédito entre el sector público y privado debe volverse al nivel de la proporción del año 1978. Se debe evitar presiones monetarias indeseables del financiamiento del Banco Central al gobiemo. En cuanto a la polfitica fiscal se propone una polftica de austeridad, condicionada por las necesidades financieras de la guerra. Aparte de la posibilidad de reducción de gastos por la reprivatización de actividades, se plantea la necesidad que los gastos corrientes sean aubientos por 
los ingresos corrientes y que la inversión pública sea financiada por recursos extemos para evitar la reducción del crédito interno destinado al sector privado. Por el lado de los ingresos fiscales, no se debe aumentar la carga tributaria al público, pero se debe aumentar el peso de los impuestos directos en comparación con los indirectos. Con respecto al sector extemo el modelo aboga por el establecimiento de un tipo de cambio más realista y así también por reducir gradualmente los aranceles, para poder pasar de una estructura industrial intensiva en capital a la producción para la exportación intensiva en mano de obra (¿barata?).

Finalmente se puede mencionar que el modelo plantea la necesidad de la participación del sector privado en la comercialización de la producción exportable "para que el productor pueda tomar las decisiones que inciden directamente en su actividad productiva" (FUSADES, 1985: 50). Obviamente se está haciendo referencia a la reforma de la comercialización externa del café y azúcar y el monopolio del Estado en ésta.

Hemos presentado extensamente los dos modelos básicos de la política económica de El Salvador con la finalidad de obtener un marco de referencia con suficientes niveles de detalles para poder evaluar las políticas implementadas durante los anos 80 . Ambos modelos tienen en común la preocupación por el financiamiento de los gastos de guerra. Muy notorias son las diferencias en cuanto a la orientación de la reactivación económica hacia el mercado intemo o extemo y referente al papel del Estado en ésta. Por otro lado, destaca la cercania, para no decir concordancia, del modelo de FUSADES con las más importantes políticas de estabilización y de ajuste del FMI, ya sean éstas en el área de la polltica fiscal, monetaria y crediticia, de la balanza de pagos 0 con respecto a los precios internos (Lichtensztejn, 1984).

\section{La polftica económica de las Juntas de goblerno: '1980-1981}

El programa de emergencia nacional de 1980 anunciado por Duarte como Presidente de la tercera Junta de gobiemo después del golpe de Estado de 1979, siguió los lineamientos básicos de las reformas con intentos de aumentar el empleo y garantizar la satisfacción de las necesidades básicas de la población. Esta politica fue acompanada por una fuerte represion, dirigida principalmente hacia el movimiento sindical y huelguista en ascenso en las ciudades. Dos intentos de efectuar un paro nacional, respectivamente en junio bajo la dirección de la Coordinadora Revolucionaria de Masas de carácter reivindicativo y otro en agosto de 1980 orientado por el Frente Democrático Revolucionario 
(FDR) con exigencias políticas fueron fuertemente reprimidos y no prosperaron (Dunkerley, 1982; 161-167). La implementación de la primera fase de la reforma agraria en el campo se realizó con la intervención directa del ejército, mediante la ocupación militar de aproximadamente 470 grandes propiedades, abarcando el 16\% del área agrícola del país y la expulsión de las bases y militantes del movimiento popular. Mediante implementaciones posteriores se extendio el alcance de la reforma al $23 \%$ del área agrícola, beneficiando al igual porcentaje del total de las familias rurales.

La política económica estimuló la demanda intema con la aprobación de alzas limitadas de los salarios en el campo y la ciudad, el control de precios de ciertos productos básicos de consumo popular (maíz, frijol, arroz, carne de pollo y huevos) y otras medidas regulatorias por parte del Instituto Regulador de Abastecimiento (IRA). Los salarios reales generalmente habian mejorado, a pesar del aumento en la tasa de inflación (cuadro 2). Por otra parte, fueron canalizados créditos y recursos externos a sectores claves de la producción, principalmente la agricultura. El crecimiento del aparato y las actividades militares consumió igualmente muchos recursos, sobre todo de procedencia extema y "ciertas ineficiencias en el uso de los fondos fueron inevitables en el lío de los primeros días del nuevo gobiemo"."

La política monetaria y crediticia expansionista aumentó el déficit del gobiemo central de los niveles de menos del $1 \%$ al $5 \%$ del PIB y se quintuplico el uso, por parte del gobiemo, de recursos crediticios internos, que obligó al Banco Central de Reservas (BCR) a aumentar significativamente sus créditos domésticos por el segundo ano consecutivo. En 1979 el BCR tenla que ampliar sus créditos para cubrir las necesidades del sector privado por la fuga masiva de capital y la reducción sustantiva de los créditos de proveedores externos. La fuga también redujo el nivel de las reservas internas para el año siguiente, a pesar del superávit en la cuenta corriente (cuadro 2). El gobiemo no logró cumplir con las condiciones en téminos de una política de reducción del crédito al sector público y privado establecidas por un programa de "stand-by" del Fondo Monetario relacionado con un préstamo aprobado a mediados del ano y destinado a mejorar la situación de la balanza de pagos (IMF, 1982: 6). Se prevela que las necesidades de nuevos recursos podrlan ser cubiertos por los ingresos provenientes de aumentos en la exportación del café. No se había tomado en cuenta el nivel ya extraordinariamente elevado de estas exportaciones en 1979. La reducción posterior afectó los ingresos de impuestos de exportación y del sector cafetalero. 
El programa de austeridad de 1981 fue orientado principalmente por los intentos de mejorar la situación del desequilibrio externo. Fue relacionado con la solicitud de compra del $50 \%$ de la cuota por el FMI a cargo del tramo compensatorio, justificado por la baja en las exportaciones. Los principales instrumentos fueron el control a las importaciones y otros pagos al exterior y al congelamiento de los salarios mediante el Decreto 544 y medidas de control de precios de productos de consumo básico.

Las politicas monetarias y fiscales fueron más restrictivas que en el año anterior con la reducción significativa en la expansión del crédito del BCR, el aumento en los impuestos domésticos (indirectos) y la restrioción en el crecimiento de los gastos del sector público. Los gastos corrientes (excluyendo gastos militares) y de inversión disminuyeron en términos reales. La producción total decreció más rápido que los gastos del gobiemo, resultando en una duplicación del déficit fiscal y un aumento como pocentaje del PIB en comparación con el ano anterior (cuadro 2). La continua baja en las exportaciones tenla sus efectos negativos, tanto en los ingresos fiscales, como en la demanda agregada del pais.

La ofensiva generalizada del FMLN iniciada en enero de 1981 marcos el cambio en el accionar del movimiento popular, de las manifestaciones y huelgas hacia acciones armadas. La represión generalizada exigla un fuerte incremento en el número de efectivo de las fuerzas armadas, en su armamento y en los correspondientes gastos. Las ofenslvas militares y el bombardeo masivo de las áreas rurales cobraban muchas victimas en la población civil y aceleraba el éxodo rural.

La oligarqula, por otro lado empezó a organizarse de acuerdo con la nueva situación sociopolitica mediante la reactivación de sus asociaclones gremiales como la poderosa asociación de empresas privadas (ANEP), la asociación de cafetaleros (ASCAFE), etc. y la fundación de un partido politico de extrema derecha, Alianza Republicana Nacionalista (ARENA) que empezó a disputarte al PDC el nuevo espacio politico, con miras a las elecciones del próximo ano. Como principales puntos de discordancia del sector privado con el gobierno se puede senalar la reforma agraria, el monopolio de la exportación de café del Instltuto estatal INCAFE y la falta da avances en el campo militar frente a la guerrilla, que impactaba sobre todo a los algodoneros en el Este del pais. Por otra parte, cabe senalar que las reformas introducidas de ninguna manera han eliminado la capacidad de los grandes cafetaleros con beneficios propios y otros sectores del gran capital privado, de 
apropiarse de una parte elevada del excedente generado (véase p. e). Orellana et. al., 1986). Igualmente en el proceso de nacionalización de la banca, bs ex duenos habian obtenido altas compensaciones (Instituto de Investigaciones Económicas, 1982: 524).

\section{El goblerno de unldad naclonal: 1982-1983}

Estos anos apuntan a cambios cualitativos en la economía, tendientes a estructurar una economía de guerra, mientras que los enfrentamientos bélicos causaban cada vez más daños a la economía, traduciéndose en distorsiones cada vez mayores en el aparato productivo (Instituto de Investigaciones Económicas, 1983: 439-458).

En el último trimestre de 1982 y a comienzos de 1983 las grandes ofensivas militares de las organizaciones miembros del Frente de Liberación (FMLN) representaron fuertes golpes económicos y políticos al gobierno. Así también de destructivo fue el sabotaje económico a la producción, al transporte y almacenamiento de productos agrícolas de exportación y la infraestructura (puentes, red eléctrica, medios de comunicación y otros) a que se daba comienzo. La participación directa de los grupos oligárquicos en la dirección estatal, legitimada por el proceso electoral en 1982 y consolidada con el 'Pacto de Apaneca' que resultó en la formación del nuevo gobierno de unidad nacional, habia significado la intensificación de la guerra.

Los partidos ARENA y el Partido de Conciliación Nacional (PCN) de dominación oligárquica controlaron los ministerios de mayor peso económico. El programa de ajuste o de reactivación económica, elaborado en 1982 con la orientación del Fondo Monetario, tenía como eje central la reasignación de recursos hacia la satisfacción de necesidades militares, tanto en términos del accionar armado, como para consolidar las alianzas que sirven a este como base de apoyo. El carácter recesivo hacia el mercado interno de este programa se desprende de las diferentes políticas económicas planteadas. En el sector externo se intentó reducir las importaciones con la apertura del mercado paralelo de divisas. Igualmente se proponía bajar la tasa de expansión monetaria y disminuir los gastos fiscales. Se mantenía la congelación de salarios del período anterior, acompanada por una creciente liberalización de precios.

Es dificil estimar los efectos de esta política porque la economía se veía también afectada por algunos fenómenos de la naturaleza como la sequía a mediados del 1982, el temporal del mismo ano y la tardanza en las lluvias en 1983. La demanda y oferta total a precios constantes llegaron en este período a los niveles más bajos de la década; a pesar 
de la tendencia ligeramente positiva en 1983. Las tasas de desocupación alcanzaron niveles elevados, el $27.41 \%$ de la población económicamente activa (PEA) en 1982 y el 32.24\% en 1983.4 La restricción a las importaciones estuvo acompanada por reducciones en la producción de prácticamente todos los sectores productivos. Las tasas de crecimiento del PIB fueron negativos por tres anos consecutivos de 1980-1982, tanto para el sector agropecuario, como también para la industria, la construcción, el comercio y los servicios (cuadro 1). La producción de la agricultura fue afectada negativamente por los factores naturales mencionados anteriormente. También influyeron la mala administración de la reforma agraria, la poca colaboración de los duenos de grandes extensiones de tierra y la guerra que afectó sobre todo al cultivo del algodón.

Los sectores secundarios sufrieron relativamente los más fuertes descensos, entre otras razones debido a las restricciones en la importación de las materias primas y bienes intermedios, el funcionamiento del mercado paralelo de divisas y el cierre de cientos de fábricas y empresas por estos motivos, la fuga de capitales y la situación de guerra en general. En cuanto al capital fijo se redujeron sobre todo las inversiones públicas a precios constantes, mientras que las inversiones privadas mostraron una ligera recuperación (cuadro 2). El consumo privado global, por otro lado, se redujo a los niveles más bajos de la década.

Revisamos ahora los resultados de esta política de ajuste con respecto a los principales balances externos e internos de la economia (cuadro 2). El déficit en la balanza comercial se redujo en 1983 gracias a la disminución en las importaciones. Igualmente pudo disminuirse, aún más, el saldo negativo en la cuenta corriente debido al fuerte aumento de las transferencias en forma de donaciones procedentes del gobierno de los Estados Unidos y las remesas enviadas por los salvadorehos residentes en este pals. La ayuda de seguridad (Economic Support Fund más el apoyo de carácter directamente militar), llegó a niveles muy altos y ascendió a más de US\$200 millones por ano, niveles que en la región centroamericana no tenía precedencia. Fue también en estos anos en que la participación de las donaciones en la ayuda norteamericana superaba a la de los préstamos.

La fuga de capitales continuó, pero a niveles más bajos que los anos anteriores y sus efectos negativos fueron compensados por el flujo de préstamos y donaciones extemos, tanto del FMI como de otras instituciones internacionales y gobiernos, entre los cuales destacan, los proporcionados por la Agencia Intemacional de Desarrollo (AID) de los 
Estados Unidos. Muchos de los fondos fueron destinados para financiar proyectos de reparación a la infraestructura danada en las zonas de guerra. Asi, habian préstamos del Banco Interamericano de Desarrollo (BID) para la reconstrucción del dinamitado Puente de Oro, la construcción de carreteras rurales en la provincia de Chalatenango, uno de los baluartes de la guerrilla y unos US $\$ 100$ millones para la reapertura de fábricas cerradas por la guerra. De manera que en estos dos anos se lograron significativos aumentos en las reservas intemacionales netas, llegándose en 1983 por primera vez después de 1979, a un valor positivo de estas reservas de US\$121,3 millones (MIPLAN, 1988: Anexo 1, cuadro 9). La deuda externa a mediano y largo plazo del sector público y bancario, aumentó fuertemente en este periodo (cuadro 2).

Otro hecho importante, es el balance alcanzado en el déficit fiscal que, previo a la ayuda norteamericana, alcanzaba altos niveles, para ser más concretos, un $10 \%$ del PIB, financiado mayormente con recursos externos (MIPLAN, 1987: Anexo 1). Por otro lado, se nota de los datos del cuadro 2 que habia reducción en los ingresos fiscales que a pesar de las disminuciones del PIB bajaron su participación hasta porcentajes comparables con la de la década de los 60 . En cuanto a los egresos del gobierno se puede mencionar que aparte de las reducciones en las inversiones públicas senaladas, se dió un congelamiento de plazas en el sector público para contratación de personal que era válido tanto para el Gobierno central, como para las instituciones autónomas, logrando asl, que el total de empleados estatales no sobrepasara las 72,000 plazas (FUSADES, 1986a: 23). Esta cifra no incluye el personal de defensa y seguridad pública, que contaba a finales de 1983 con más de 30,000 efectivos, comparado con los 12,000 en $1979^{5}$. Los gastos de los cuerpos de seguridad (policia, ejército y otros) tuvieron un incremento elevado, alcanzando el $21.4 \%$ del presupuesto total de la nación (cuadro 3 del anexo). El aumento de esta participación en el gasto gubernamental con un $50 \%$ con respecto a las de 1979 podrla considerarse como limitado si lo comparamos con la casi triplicación del número de miembros de las fuerzas armadas y otros cuerpos de seguridad del Estado. La diferencia fue cubierta por la ayuda militar directa de los Estados Unidos, cuyo monto crecio de \$6.4 millones en 1980 a $\$ 166.9$ millones en 1983 (Rosa, 1987: 83 y 123).

Se podla mantener la tasa inflacionaria por debajo del $15 \%$ anual (cuadro 2). Sin embargo, por la congelación de los salarios y el creciente desempleo se puede deducir que hubo un empeoramiento en las condiciones de vida de la población, ampliándose esta situación, por primera vez, a sectores que conforman las capas medias, como los empleados públicos, los profesionales, los trabajadores por cuenta pro- 
pia, etc. (Instituto de Investigaciones Ecnómicas, 1983: 454).

Revisando ahora el desarrollo de la política económica durante todo el período 1980-1983, o sea el período anterior al gobiemo del PDC, podemos constatar una tendencia progresiva hacia la neutralización de los efectos de las reformas económicas. La mayoria de los programas económicos introducidos por sendos gobiernos tenian mayormente un carácter recesivo y no se orientaron al desarrollo del mercado interno para reactivar la economia, a pesar del creciente papel regulador del Estado y el apoyo a las reformas por parte de la Democracia Cristiana, algunas agnupaciones gremiales, una fracción de los militares y del gobierno de los Estados Unidos.

Se puede mencionar tres factores importantes que han influido en el desarrollo de esta tendencia La contrainsurgencia en su forma de guerra abierta contra el movimiento popular requeria la reasignación de muchos recursos hacia necesidades militares. La reparación de los daños de guerra y las grandes campanas militares para desplazar a la guerrilla de sus retaguardias estratégicas demandaron una política económica orientada a restringir la demanda pública, requisar los ingresos populares y aumentar la oferta agregada militarizada.

La recuperación del terreno perdido por los grupos dominantes de la economia y su adecuación a las nuevas condiciones, fue otro factor de peso. Durante el bienio 1982-83, fueron ellos quienes estuvieron al mando del aparato económico y financiero del Estado. El reajuste del modelo reformista hacia uno de carácter más tradicional fue un hecho. Sin embargo, se sigue necesitando el Estado regulador por to menos para organizar el aparato represivo y llevar a cabo la guerra en todos los campos.

En tercer lugar, la necesidad de acudir al FMI y otras instituciones internacionales fortaleció la política económica del ajuste aplicada en el bienio, que se orientó hacia la estabilización mediante la restricción de la demanda interna y el uso de los recursos externos para dinamizar la economia.

La política económica no logró sus obejtivos, ni siquiera en términos de los indicadores tradicionalmente utilizados. En estos anos no hubo crecimiento, ni equilibrio fiscal, ni tampoco mejoras en la cuenta corriente de la balanza de pagos, si no fuera por los fuertes ingresos de donaciones extemas oficiales y privadas. Habian aumentado considerablemente las reservas netas externas en 1983 gracias a los préstamos concedidos a mediano y largo plazo al sector público, provenientes de los Estados Unidos, las instituciones internacionales y otros paises. EI 
carácter regresivo de la política económica habia eliminado la poslbllidad de atenuar el descontento de la población. Por otra parte, el manejo económico no habia logrado parar la fuga de capitales, que indica que no se habia restaurado la confianza de la clase dominante en la economia.

\section{Los dos primeros anos del goblerno de la Democracla Cris- tlana: 1984-1985}

Este periodo dió inicio con el abandono del programa de estabilización económica aplicado en los anos anteriores y con la introducción de un conjunto de políticas de mayor consistencia con los lineamientos reformistas de 1980. La orientación general del nuevo programa era hacia la expansión de la demanda interna, la profundización de las reformas, el estímulo de las exportaciones agrícolas e industriales no-tradicionales y una mayor asignación de recursos para financiar una nueva modalidad de guerra contrainsurgente.

Una política monetaria, crediticia y fiscal expansiva, la mayor intervención estatal, la redistribución equitativa de los costos de la guerra y un fuerte aumento en la disponibilidad de ayuda extema procedente de los Estados Unidos, fueron considerados como necesarios para efectuar esta política. La formulación articulada del programa no fue dado a conocer en el Plan "Camino hacia la Paz", sino hasta en 1985, después de dos exposiciones preliminares e incompletas en 1984 por respoctivamente los ministros de Economia y de Planificacion?'.

Esta reorientación en la política económica fue hecho posible por la confluencia de varios factores. Entre ellos se debe mencionar el desplazamiento de los representantes políticos de la oligarquia de la cúspide del aparato estatal, debido a sendas victorias electorales del PDC. Como elementos explicativos de ello se puede senalar, aparte de la tradicional incidencia electorera democristiana en el campo y en la capital, el pacto social entre Duarte y las tuerzas reformistas en el movimiento popular, principalmente la Unidad Popular Democrática (UPD) formada en 1982 y las cooperativas de la reforma agraria; el apoyo internacional de los Estados Unidos y sus aliados y el apoyo tácito de una fracción importante en las fuerzas armadas. Esto tenía que ver también con el cambio en la estrategia militar hacia la guerra de baja intensidad de prolongada duración, ya que con las ofensivas y bombardeos masivos del período anterior el ejército logró desplazar pero no eliminar a la guerrilla.

La ayuda económica de los Estados Unidos, como consecuencia de la nueva estrategia, signifiob un aumento considerable en la dispo- 
nibilidad de divisas, con el cual el gobierno de El Salvador podia permitirse el lujo de no acudir al FMI para nuevos préstamos, ampliándose de esta manera los márgenes para una política económica diferente. Los recursos externos fueron destinados a la reparación de las consecuencias de guerra, la reducción del déficit fiscal, los créditos a la empresa privada y a sostener la balanza de pagos en general.

Veámos la implementación concreta de las medidas referidas y sus efectos en función de los objetivos establecidos. En la política tributaria únicamente se logró aumentar marginalmente la carga tributaria con respecto al bienio anterior (cuadro 2: ingresos tributarios en relación al PIB). Esta creció a puras penas el $1.6 \%$ en comparación con el bienio anterior y decreció en un $2 \%$ en relación a la media aritmética de los últimos cuatro anos de la década anterior. Los impuestos indirectos fueron básicamente responsables para el aumento en los ingresos del fisco, el timbre fiscal (fácilmente trasladable al consumidor) y los impuestos a la importación (debido a la eliminación de ciertas restricciones de importaciones de artículos suntuarios para aumentar la recaudación). Por otro lado, bajaron las participaciones de los impuestos sobre la renta y el patrimonio.

Los gastos del gobiemo central crecieron fuertemente, sobre todo los corrientes. La formación bruta de capital fijo del sector público a precios constantes se redujo significativamente (cuadro 2). Los gastos por servicio de la deuda pública crecieron. Otro rubro expansivo tue el de los gastos militares. Defensa y seguridad pública llegaron a absorber más de la cuarta parte del presupuesto (cuadro 3). La ayuda oconómica y militar de los Estados Unidos llegó a \$500 millones por ano, mientras que casi el $60 \%$ de la ayuda económica tenía que ver indirectamente con la guerra (Hatfield et. al., 1987: 33). Se dió un crecimiento de las fuerzas armadas y los cuerpos de seguridad alcanzando la cifra de $\mathbf{5 0 . 0 0 0 ~ h o m b r e s . ~ L a s ~ a c c i o n e s ~ m i l i t a r e s ~ y ~ t a m b i e ́ n ~ l a ~}$ introducción de grandes campanas de carácter civico-militar como la de la Comisión Nacional de Reparación de Areas (CONARA) y "unidos para reconstruir" fueron responsables de este aumento.

Los nubros del servicio a la deuda, la defensa y seguridad pública llegaron a ocupar casi la mitad de los gastos públicos, en detrimento de los gastos sociales y de obras públicas cuya participación bajó en este perlodo (auadro 3). También hubo un incremento en las plazas de personal para el gobiemo central y de las instituciones autónomas llegando a alcanzar la cifra record de 79.000 empleados, lo que no sólo tenla que ver con la mayor actividad y burocratización del aparato estatal, sino también con la nueva política de alianzas del PDC. 
La consolidación de la reforma agraria, tanto con respecto a la formación de las cooperativas de la fase I, como la implementación de la fase III, figura entre los logros importantes de las acciones del Estado dirigidas a dinamizar el agro y a ampliar la base social del gobierno.

Ahora bien, se puede decir que no todas las políticas aplicadas fueron erróneas. Asi, uno de los logros de este periodo fue la reducción del déficit fiscal total al final de 1985 a más o menos el $3 \%$ del PIB después de la ayuda externa (cuadro 2). En la evaluación del alto porcentaje del $12.5 \%$ del déficit total en 1984 se tiene que tomar en cuenta el considerable déficit inicial como resultado de la gestión del gobierno de Unidad Nacional durante el bienio anterior y la amortización extraordinaria de la deuda pública interna de aproximadamente US\$ 200 millones (entre otros para cancelar parcialmente la deuda agraria de la reforma a los exduenos). Ambos montos representaron conjuntamente a casi las dos terceras partes del déficit total de 1984. El financiamiento del déficit fiscal de los dos anos de gobierno de la DC, aqui revisados, corrib a cargo del financiamiento externo por la AID en aproximadamente un 44\% (MIPLAN, 1987: Anexo 1).

En estos mismos anos el sistema bancario nacionalizado expandió fuertemente los créditos al sector privado en un $10.1 \%$ en 1984 y un $26.2 \%$ en el ano siguiente, que comparado con una tasa promedio del $5.5 \%$ en el periodo 1979-1983, resulta ser muy significativa. Las tasas de interés se redujeron también en 1984 (Sánchez, 1986: 542). Al igual ritmo crecieron los créditos al. sector público, sobre todo el gobierno central (FUSADES, 1986b: 13).

La intención de fomentar las actividades industriales destinadas al mercado interno en general y a la exportación de productos no tradicionales, hace necesario revisar el destino más preciso de los créditos otorgados y compararto con el periodo anterior. De alguna información incompleta al respecto, se deduce algo de la nueva orientación (BCR, 1986). Las participaciones de la industria y construcción manifestaron respectivamente un aumento y un porcentaje estable dentro del total de los créditos otorgados por los bancos comerciales e hipotecarios. Las reformas a las líneas de crédito al sector industrial y de su fondo de reactivación en 1983, son medidas que han favorecido al sector.

La política de control de precios se concretizó en varias medidas que no todas fueron efectivas. La compra de granos básicos a precios fijos por el instituto regulador estatal IRA podía realizarse sin muchos problemas, sobre todo del nuevo sector reformado. La ley de esta- 
bilización de precios, la creación de la comisión de defensa del consumidor y los intentos de fijar los márgenes de ganancia de los distribuidores de repuestos fracasaron, sobre todo por la acción del sector privado comercial.

Otro factor de destabilización de precios fue el progresivo funcionamiento del mercado paralelo de divisas. A finales de 1985 quedaron solamente las importaciones de insumos para medicinas, fertilizantes, aceites, petroleo y bienes de capital relegadas al tipo de cambio oficial (Sánchez, 1986: 546). Después de una inflación moderada del $11.5 \%$ en 1984, el índice de precios al consumidor tuvo un aumento del $22.3 \%$ al ano siguiente, manifestándose fuertes alzas en los rubros de vestuario y productos relacionados al mismo y de vivienda. La explicación del BCR, que este fenómeno fue provocado por la mayor circulación de la masa monetaria que resultó en un incremento de la demanda de bienes suntuarios, no nos parece como la más adecuada si revisamos la política salarial del periodo (BCR, 1986b: 31). Por otra parte, si examinamos el consumo privado total a precios constantes, se observa los magros aumentos del 4\% en 1984 y el $3 \%$ en 1985, supuestamente el ano de mayor circulación monetaria.

Las primeras medidas en el campo salarial fueron la derogación del decreto 544 de congelación de los salarios y el otorgamiento del incremento salarial para el sector público a mediados de 1984. Fueron medidas insuficientes para evitar la fuerte reducción en los niveles de los salarios reales (cuadro 2). La pérdida del poder de compra por las grandes mayorlas de la población debido a la creciente inflación, la falta de perspectivas de empleo con las tasas de desocupación que no bajaron de la tercera parte de la PEA y la ausencia de participación en la gestión económica, desembocaron en la ruptura del pacto social entre el gobierno y su base gremial.

Una parte significativa de los trabajadores organizados coparon rápidamente los márgenes surgidos por la nueva estrategia contrainsurgente de baja intensidad y realizaron nuevamente acciones reivindicativas. Como ejemplo podemos mencionar una serie de huelgas en febrero 1984, entre ellas las del Instituto del Seguro Social, IRA y ANDA (empresa autónoma del agua), acompanadas por algunos paros en el sector privado. En marzo de mismo año se dieron huelgas en los Ministerios de Obras Públicas, de Agricultura, el Instituto de la Reforma Agraria ISTA v otras. La huelga más larga de 43 dlas la mantenlan los trabajadores del Correo Nacional, tradicionalmente de orientación democristiana.

Este movimiento finalmente dió como resultado un incremento 
ealarial general de 130 colones (\$42) para el sector público en jullo 1984. En 1985 se dieron 65 paros laborales en los cuales se involucraron 46 organizaciones gremiales (Sánchez, 1986: 547). A modo de comparación podemos mencionar al ano 1979, con 103 conflictos laborales formalmente registrados por el Ministerio de Trabajo.

La última categorla de medidas económicas de los primeros anos del gobiemo de Duarte que discutimos es la referente a la balanza de 2agos. Las exportaciones siguieron estancadas tanto en cantidades somo en precios. El ligero mejoramiento de los ingresos del café en comparación con el bienio anterior fue prácticamente neutralizado por el desconso en las exportaciones del algodón y las exportaciones destinadas al MCCA, mayomente de carácter no-tradicional, a pesar de las ventajas ofrecidas por el tipo de cambio del mercado paralelo.

Las importaciones a precios constantes aumentaron marginalmente con respecto al bienio anterior, pero por los aumentos en sus precios (en dólares) hicieron aumentar fuertemente el déficit en la balanza comercial (cuadro 2). Por otra parte quedaron estancadas a bs bajos niveles de los últimos anos las importaciones de bienes intermedios y de capital, sobre todo con destina a la industria y la construcción, limitando de esta manera el crecimiento productivo de la oferta global.

La formación de capital fijo a precios constantes fue restringido en el sector público, pero en el sector privado manifestaron por primera vez en la década incrementos porcentuales mayores del $10 \%$ gracias a la canalización a este sector de la ayuda externa procedente de la AID. Empero, los niveles absolutos de estas inversiones no alcanzaron ni lejos los valores a precios constantes en 1979. El flujo de las donaclones públicas y privadas de refugiados en los Estados Unidos creció nuevamente a niveles sin precedencia, sin embargo el saldo en la cuenta corriente mantenla su bajo valor negativo en ambos anos, tal como demuestra el cuadro 2. Sin embargo, el ingreso de nuevos préstamos oficiales a largo y mediano plazo y la reducción en la fuga de capitales, resultaron ser pequenas mejoras en los niveles de reservas internacionales en ambos anos, pero menores que en el bienio anterior.

El ano 1985 terminó con un nivel de reservas suficiente para financiar nueve semanas de importaciones y pago neto de servicios (en comparación con las seis semanas al final de 1983). La mayor parte del déficit en bienes y servicios fue cubierto por las donaciones y los préstamos netos de la AID: en el bienio 1982-83, fue por un total de $65 \%$, mientras que este porcentaje aumentó al $82 \%$ en los dos primeros antos de Duarte (MIPLAN, 1987: Anexo 2). El nubro de mayor peso dentro de las donaciones de la AID fue la asistencia al sector privado. 
En 1984-85 ingresaron US\$295 millones por este concepto, es decir el $74 \%$ de un total de donaciones de la AID de \$396.6 millones (las cifras para el bienio anterior: US\$220 millonec o sea el $81 \%$ de US\$ 270.5 millones de donaciones AID).

Concluyendo la discusión sobre la política durante los dos primeros anos del Gobierno de la DC, orientada hacia el desarrollo del mercado interno, se puede senalar que se habia logrado detener el decrecimiento del PIB en términos reales sin haber recuperado el nivel absoluto del ano 1981. De las tasas de crecimiento del cuadro 1 se observa en casi todos los casos valores positivos, con excepción de la construcción en 1984 y el agro en 1985. El crecimiento durante el bienio, especialmente de los sectores productivos fue insuficiente, para neutralizar el decenso de los primeros cuatro años de esta década.

En cuanto a los principales balances macroeconómicos, como son las reservas internacionales, el déficit fiscal y la inflación, se nota aparentemente una estabilización, si no una mejora como es el caso del déficit fiscal. Empero, la política en su totalidad no habla sido congruente, ni en términos de las medidas tomadas, ni en cuanto a los efectos percibidos. No se ha logrado trasladar el eje de acumulación, ni siquiera tendencialmente, hacia las exportaciones no-tradicionales 0 el mercado interno. El deterioro de las exportaciones hacia el MCCA se aceleró y la participación de éstas en las exportaciones totales bajó hasta la mitad del porcentaje en 1980. Las políticas económicas expansivas en beneficio de la rentabilidad del sector privado fueron aprovechadas mayormente por el gran capital agroexportador y comercial y de construcción. La clase media alta urbana logró fortalecer su posición, aprovechándose de ganancias extraordinarias de la guerra, de la cornupción y de la situación de crisis generalizada. Ninguna fracción de capital se hizo cargo del pretendido nuevo modelo de acumulación (para un análisis histórico del problema véase Pelupessy, 1987). Más bien había una creciente unidad de acción entre las distintas fracciones del capital, por ejemplo en el caso mencionado de los distribuidores de repuestos.

La reducción, de hecho, del papel del Estado en el proceso de acumulación restringe las posibilidades para redistribuir más equitativamente los gastos de la guerra y para la reorientación del eje de acumulación.

Por otra parte, fracasaron también los intentos de construir una base popular firme para el nuevo modelo, relacionado con las necesidades de la guerra de baja intensidad y sus correspondientes acciones clvicomilitares. En el ámbito de las fuerzas armadas es donde el gobierno 
parece haber logrado algún éxito en desplazar por lo menos temporalmente las fuerzas que proponen la guerra abierta, gracias al manejo de la ayuda norteamericana y de las prioridades dadas en el presupuesto a los gastos de defensa y seguridad pública. Estos gastos limitan la mayor disponibilidad de recursos para las inversiones infraestructurales y sociales necesarias para apoyar a la nueva estrategia de contrainsurgencia.

Con todos estos problemas era obvio, a fines de 1985, que se requerla un ajuste en la política económica para enfrentarse con los desequilibrios que tienden a ser mayores en 1986 y que no existlan alternativas para superarlos con las políticas aplicadas hasta la fecha. Hubo también inconsistencias en los planteamientos sobre la política economica por parte del Gobierno de los Estados Unidos, fuente principal de la ayuda extema. En varios de los informes de la AID o de la Controlarla estadounidense sobre la canalización de la ayuda, se observan presiones a cambiar la orientación de la política del Gobierno de Duarte hacia una de mayores semejanzas con las propuestas del FMI (Comptroller General US, 1985). A pesar de la declaración conjunta de los presidentes Ronald Reagan y Napoleón Duarte, de apoyar al proceso de reformas estructurales en El Salvador, se está presionando para el cambio hacia una política más recesiva y una participación menos activa del Estado en la actividad económica.

\section{La politica de ajuste: 1986 en adelante}

La respuesta del Gobierno de Duarte ante los problemas después de los primeros 19 meses de su gestión fue el anuncio a comienzos de 1986 del "programa de estabilización y reactivación económica", comúnmente conocido como primer paquetazo. En la presentación el presidente to calificó como el ordenamiento de los factores económicos para "establecer las bases de un nuevo modelo socioeconómico..." Los principales objetivos anunciadas fueron la reducción del déficit fiscal y su financiamiento por el BCR hasta un máximo de 100 millones de colones para 1986 ( $\$ 20$ millones), la reducción de la expansión monetaria sin afectar el crédito al sector privado, mejorar la situación de la balanza de pagos, la reactivación de la producción y la protección del ingreso popular.

El carácter de esta nueva política se desprende claramente de los instrumentos aplicados. La unificación del tipo de cambio al nivel 'realista' de cinco colones por dólar fue la más importante medida en el sector externo, favoreciendo a los productores agroindustriales, el INCAFE y todo aquello que maneja los recursos externos por concepto 
de la ayuda, préstamos e inversiones extranjeras. La medida también deberá reducir las importaciones. El mismo efecto se preverá de la prohibición temporal de algunas importaciones sunturias y del impuesto selectivo al consumo de bienes no esenciales importados de fuera de Centroamérica.

En el ámbito fiscal fueron introducidos nuevos impuestos, como el impuesto temporal de ganancias extraordinarias de la exportación del café (aumento del impuesto existente con 15\% cuando el precio internacional exceda US\$135 por quintal) ${ }^{0 *}$, impuesto selectivo al consumo, la consideración de las instituciones autónomas como empresas privadas para los impuestos, la ampliación del sistema de retención de impuestos sobre la renta a contribuyentes no-asalariados y la supresión del papel sellado de menos de 40 centavos $(\$ 0.08)$. El porcentaje del impuesto al café fue reducido al $10 \%$ posteriormente, por la presión de los cafetaleros.

Para aliviar el problema de la escasez del transporte colectivo causado por la guerra se eximía autobuses de los impuestos a la importación.

Por el lado de los gastos se decidió conceder un aumento salarial de C 150 mensual $(\$ 30)$ a los empleados públicos y mantener la mayoria de los subsidios a la canasta básica y los combustibles (estos subsidios no podian neutralizar el efecto alcista de la devaluación). En la política crediticia se planteó la expansión del crédito total con un $20 \%$ en 1986, aumentándose ligeramente el peso de la industria en este a costa del comercio.

Se aumentaron las tasas de interés activa y pasiva de los depósitos a plazo y de cuentas de ahorro programado, quedándose igual el resto de las tasas pasivas.

En la política de ingresos se incrementaron los salarios mínimos de todos los sectores, variando el aumento del $15 \%$ en el sector urbano en San Salvador al $74 \%$ para las mujeres trabajadoras rurales,como consecuencia del mencionado aumento salarial en el sector público. El gobierno propuso al sector privado para realizar un aumento general de salarios del $10 \%$ al $15 \%$, que en el sector urbano fue logrado solamente para la tercera parte de los asalariados.

Se congelaron temporalmente los precios de la canasta básica y de los servicios básicos como alquileres, luz y agua, etc. A algunos productos se les otorgó aumentos limitados en sus precios, tales como la margarina $(5 \%)$, el aceite vegetal $(3 \%)$, el transporte público urbano $(20 \%)$ y los combustibles. Sin embargo, varias de las medidas expues- 
100 tenlan también un efecto inflacionario inmediato: la devaluación, el papel sellado, el aumento en algunas tasas de interés, etc. En los primeros dlas después del anuncio del paquetazo aumentaron los precios con aproximadamente el $20 \%$ en promedio.

La insuficiencia de los aumentos salariales decretados impulsó una nueva ola de acciones reivindicativas, exigiendo la derogación de las medidas que perjudican a los trabajadores y sus familias. Como respuesta inmediata se formó la central "Unidad Nacional de los Trabajadores Salvadorenos" (UNTS) en la cual participaron tanto federaclones sindicales tradicionales opositores al gobierno, como también agnupaciones más afines a éste como la UPD, algunos sindicatos de orlentación de la CLAT, la asociación de empleados del Ministerio de Hacienda, etc. La fundación por el gobiemo de la "Unión Nacional de Obreros y Campesinos" (UNOC) podía neutralizar hasta cierto punto el avance de la UNTS, empero no podía contener el fuerte auge del acclonar sindical en el sector público y privado. Posteriormente se retiraron la mayorla de los gremios ideológicamente no opuestos al gobierno de la UNTS, sin que por esto hubiera disminuido sus acciones reivindicativas.

Los gremios empresariales (ANEP, Cámara de Comercio, Asociaciones de Industriales, etc., unidos en la "Unidad Productiva Salvadorena"), tampoco se mostraron complacientes con las medidas tomadas, que consideraron de carácter restrictivo, intervencionista e impositivo, sin suficientes incentivos para la producción.

Lo que también resultó de dudosa eficacia fue la política fiscal (Comentario ECA, 1987: 238). Los ingresos fiscales adicionales propuestos fueron en su mayoría de tipo transitorio, como por ejemplo el caso del impuesto extraordinario a las exportaciones del café que depende del precio en el mercado mundial. Los aumentos en los gastos por otra parte, tienen un carácter permanente, como fue el caso de los aumentos salariales de empleados públicos, del servicio de la deuda externa, etc.

Para evitar la dependencia exclusiva de la ayuda externa, se dio paso a un segundo paquetazo que consistía en aumentos de algunos impuestos indirectos (cerveza, licores, gaseosas, cigarrillos), directos (al patrimonio, transferencias de bienes raices, renta de empresa, donaciones y succesiones), y sobre todo la introducción del nuevo impuesto para la defensa de la soberanía nacional. Este último consistía en una sobretasa variable al impuesto al patrimonio para capitales imponibles mayores de 100.000 colones $(\$ 20.000)$. 
Con el segundo paquetazo se estimó obtener una recaudación adicional de unos US $\$ 70$ millones, de la cual más o menos la tercera parte sería por concepto del impuesto de la "soberania". (Comentario ECA, 1987: 238-240). En contra de este paquetazo se levantaron unánimamente los gremios de todas las fracciones del capital. (Declaración conjunta, 1986: 1076), convirtiéndose ello en el más importante forcejeo político de los primeros meses de 1987 entre el gobierno y la oposición de la extrema derecha. A nivel político se organizó el 'boicot' de las sesiones de la asamblea legislativa por los miembros de todos los partidos no-democristianos, que se prolongó por algunos meses. El 22 de enero de 1987 se organizó a nivel nacional un paro empresarial, haciendo parar por primera vez en mucho tiempo a toda la actividad económica. Finalmente depositaron ante la Corte Suprema de Justicia más de 25 juicios de inconstitucionalidad del impuesto de la 'soberanla'. EI gobierno dejó sin efecto el impuesto al perder este juicio y posteriormente modifico otros impuestos del segundo paquetazo.

El gran capital no ha mostrado únicamente su poder, sino sobre todo su unidad con la cual ha podido defender sus intereses de una manera efectiva. La declaratoria de inconstitucionalidad del impuesto de guerra provocó una reacción airada por parte de las fuerzas armadas, y el ministro de defensa, el general Vides Casanova, entre otros, declaró que "entre menos recursos aporten los sectores poderosos, más diffcil es la pacificación del país... los que tienen más son los que perderán más" (citado en INFORPRESS, 1987: 14).

Sin embargo, el gobierno ha tenido que dar más incentivos al sector privado, como son por ejemplo el financiamiento de la reactivación del sector privado en la zona oriental (US $\$ 45$ millones de donación de la AID), la apertura de nuevas líneas de crédito para la cosecha cafetalera por el BCR, la baja de tasas de interés activas a actividades de exportación, créditos especiales para los algodoneros y al final de 1987 la promoción de nuevas líneas de crédito del BCR para la rehabilitación de la pequeha industria (exportaciones no-tradicionales). El gobiemo ha dado también ciertos pasos hacia una mayor influencia del sector privado en el INCAFE, proponiendo una reforma a la ley correspondiente que otorga mayor participación de este sector en la junta de gobernadores y faculta al INCAFE para delegar sus funciones de comercialización a personas naturales o jurídicas.

Si revisamos los resultados en terminos de los diferentes balances macroeconómicos para 1986 se obtiene una visión nada prometedora. Gracias a la mejora temporal en los precios intemacionales del café, creció el ingreso de divisas por este concepto, pero este efecto fue 
nuevamente eliminado por los descensos en otros rubros, como el algodón y las exportaciones hacia el MCCA. Las importaciones crecieron también, dejando un fuerte déficit en la balanza comercial (de bienes y servicios).

Sin embargo, el saldo en cuenta corriente fue positivo por primera vez después de 1980 (cuadro 2), debido a los fuertes aumentos en asistencia de la AID que superaba el saldo negativo excluyendo este Ingreso y de las remesas provenientes de migrantes salvadorenos en el exterior que habia alcanzado los montos de 300 a 400 millones de dólares por ano (MIPLAN, 1987: Anexo 1). A pesar del limitado monto neto que ingresó por la cuenta de capital podia aumentarse el nivel de las reservas internacionales a cubrir 12 semanas de importaciones de bienes y servicios.

El déficit total del gobiemo central quedó casi al mismo nivel del año anterior y equivalente al $2.3 \%$ del PIB, reduciéndose después de los donativos de AID. La deuda externa crecib hasta US\$2,200 millones a fines de 1986 con un servicio equivalente al $11.3 \%$ del PIB o casi la mitad de las exportaciones. EI PIB a precios constantes creció no más del $1 \%$, sobre todo por el decrecimiento en el agro, que neutralizó los limitados crecimientos en la producción industrial y de construcción decreciendo el PIB per cápita hacia el nivel de 1984. El terremoto de octubre 1986 destruyó a casi la tercera parte de las construcciones en la capital, haciendo crecer el déficit de viviendas a nivel nacional con un $10 \%$ y estimándose los daños materiales en mil millones de dólares. Sus efectos se nota entre otros en el mayor dinamismo del sector de la construcción, de las actividades relacionadas y en la formación de capital fijo privado y público y en las importaciones.

Los precios al consumidor crecieron con más del $30 \%$ y la tasa de desocupación abienta bajó algo con respecto al alto nivel de los años anteriores. Los asalariados perdieron en promedio más del $10 \%$ de su poder de compra en 1986, to que nuevamente ha provocado el fuerte ascenso del movimiento laboral y el rechazo generalizado de la politica oconómica aplicada.

El partido ARENA logró capitalizar el creciente descontento popular, sobre todo después de la incorporación de importantes sectores de la clase media alta urbana en sus filas y el mejoramiento de su imagen bajo la presidencia de Alfredo Cristiani, conocido empresario con ideas politicas moderadas. En las elecciones del 20 de marzo de 1988, ganó ARENA la mayorla absoluta en la asamblea legislativa y las dos terceras partes de las alcaldlas del pals, incluyendo la de la capital, tradicional puesto del PDC. Esta victoria prácticamente quebró a este 
partido y dejó al gobierno en una situación debilitado. Seguidores de ARENA también lograron desplazar los altos mandos de las Fuerzas Armadas más proclives al PDC.

Los anos 1987 y 1988 mostraron algunos tímidos mejoramientos económicos, entre otros, debido a los altos precios del café en los mercados mundiales en 1986, y el dinamismo a raiz del terremoto y la continuldad en los altos montos de donaciones oficiales y privadas del exterior. El crecimiento del PIB real superó el $2 \%$ en 1987 y llego al $1 \%$ en el ano siguiente, la inflación se redujo al $20 \%$, los déficits presupuestales quedaron a niveles manejables y la cuenta corriente del balance de pagos se mantenla positivo a pesar de fuertes aumentos en el déficit de la balanza comercial. La masa monetaria se mantenia bajo control y el tipo de cambio de cinco colones por dólar quedó inalterable a pesar de presiones intemas y extemas para devaluar. La diferencia del cambio en el mercado negro no superaba bs $10 \%$ del oficial. El endeudamiento externo se redujo muy levemente. En estos dos años empezaba una tendencia de constitución de nuevas empresas y aumentos de capital de empresas que podría reflejar cierta recuperación del sector privado.

Por otra parte segulan reduciéndose las exportaciones y la producción de productos tradicionales que no hablan sido compensados por los limitados aumentos de exportaciones no-tradicionales. El área sembrada del algodón bajó hasta la décima parte del nivel de los anos 70 , mientras que la mitad de la tierra cafetalera se encontró semi abandonada. Las ventajas que se obtenlan de la iniciativa de la Cuenca del Caribe del gobierno de los Estados Unidos han sido limitados. La mayorla de los productos de la lista de exoneraciones ya están eximidos o tienen restricciones para entrar en los Estados Unidos (López, 1986: 194).

El desempleo abierto quedaba cerca de la cuarta parte de la PEA, pero el número de subempleados y desplazados en las ciudades y refugiados en el exterior superaba el $55 \%$ de la PEA (Montes, 1988: 314). La política económica no logró disminuir la alta participación de la economla informal que creció inclusive en sectores productivos como la Industria y la construcción. Los salarios reales disminuyeron por cuarto ano consecutivo en 1988. Aproximadamente la cuarta parte de las familias salvadorenas dependen en promedio por un $60 \%$ de sus ingresos de la ayuda económica de sus familiares en los Estados Unidos para su sobrevivencia (Montes, 1988: 312 y 316).

El gobiemo y las fuerzas armadas tampoco lograron la 'pacificacion' del país y los dantos en la red eléctrica, la infraestructura y el agro cau- 
sado por el sabotaje económicodel FMLN fueron considerables.

\section{Conclusión}

En este trabajo hemos revisado la política económica de los anos 80 como "la respuesta gubernamental en lo económico a las presiones de las distintas fuerzas sociales intemas y externas en un contexto de tendencias económicas determinadas" (Sánchez, 1986: 534). Sin embargo el funcionamiento no puede ser unidireccional porque las acciones de las fuerzas sociales dependen a su vez de los mismos resultados de la política económica, que en el periodo de nuestro estudio ha tenido un carácter heterogéneo, con muchos cambios, contradicciones y reveses, a veces con efectos no previstos.

Como marco de referencia para analizar la política formulada y su ejecución hemos tomado dos modelos típicos, de la gestión económica, vinculada con los intereses de determinadas fuerzas sociales y cuyo carácter se diferencia en cuanto a la orientación hacia el desarrollo del mercado interno o externo y el grado de intervención estatal en este desarrollo. Con base en estos criterios se ha podido distinguir tres etapas de aplicación de la política económica después de la introducción de las reformas económicas básicos, como respuesta al desgaste económico, político y social del modelo de desarrollo oligárquico a fines de la década de los 70.

En la primera se vió la sustitución de la política reformista dirigida a dinamizar el mercado interno, por la política orientada hacia el mercado externo, culminándose esta etapa con el bienio de la gestión ecomónica de las fuerzas de la oligarquia. El cambio se vió relacionado con la agudización de la guerra acompanada por una reciente intervención de los Estados Unidos y la resistencia y el poderío económico de la antigua clase dominante.

Con el desplazamiento de los partidos de la extrema derecha de la gestión económica y militar por las fuerzas demócrata cristianas y sus aliados, el cambio en la estrategia de contrainsurgencia y el fuerte incremento de la participación económica de los Estados Unidos, se efectuó una segunda etapa en la política económica con mayor énfasis en el modelo reformista con intervención estatal.

En ninguna de las dos fases se había logrado la estabilización de la economía ni menos la reactivación. La política recesiva de un gobiemo dominado por la oligarquía de la primera etapa no habla mejorado los principales desequilibrios macroeconómicos. El deterioro de las condiciones de vida y de trabajo de las mayorlas fue agravado por una represión abierta y generalizada. Bajo estas condiciones no fue posible li- 
mitar el papel del Estado. Este gobierno no logró restaurar la confianza del capital privado nacional, ni extranjero. Los dos primeros anos de la gestión demócrata cristiana mostraron algunas mejoras en detener el decrecimiento del PIB y el deterioro de algunas balanzas macroeconomicas. Por otra parte, no podian parar la pérdida de poder de compra y el deterioro de las condiciones de vida de la población. La estrategia de guerra de baja intensidad cambió el carácter de la represión de abierto a selectivo.

A partir de 1986 se puede senalar un nuevo giro a la política economica dirigida nuevamente a aumentar la oferta de bienes exportables y a la restricción del papel del Estado en el manejo económico. El flujo de recursos extemos procedentes de la ayuda norteamericana ha jugado un papel básico en todas las fases mencionadas e igualmente en la orientación hacia una economía de guerra. De la ayuda militar directa de los Estados Unidos de los 80 a Centroamérica el $70 \%$ fue destinado a El Salvador. Los donativos de la AID cubrian casi la mitad de los déficits fiscales y el $90 \%$ de los déficits acumulados de la cuenta corriente de este pals y fue cubierto por la asistencia de la misma procedencia.

Sin embargo, hay que senalar que determinadas políticas económicas se compaginan mejor con cierta estrategia de guerra que otras. Asl, fue la política reformista que concuerda mejor con la guerra de baja intensidad. Con la otra política económica se puede prever un recrudecimiento de la guerra.

Del análisis de las tres etapas de la política económica en los anos 80 se desprende claramente que ha sido el modelo del ajuste que prevalece a pesar de varios intentos de implementar el modelo reformista y la preferencia ideológica del Gobiemo demócrata cristiano para este modelo. Como principales causas podemos senalar las siguientes:

a. La imposibilidad de lograr el apoyo de una fracción significativa del capital privado. La situación se agravaba con la unificación por to menos táctica de intereses de los sectores oligárquicos tradicionales y la emergente clase media alta urbana. Esta cobrada importancia con la acelarada urbanización por el desplazamiento de la población del campo a la ciudad por la guerra y la crisis económica, por la apropiación de las ganancias de la guerra y del flujo de dólares procedente de los Estados Unidos.

b. La inconsistencia en la orientación de los Estados Unidos a la gestión económica y posteriormente el cambio en la política de la AID hacia planteamientos de los organismos financieros internacionales. Por esta razón surgian muchas veces inconsistencias entre las medidas económicas y las reformas estructurales introducidas en 1980. 
c. Las necesidades y los costos de la guerra. El cambio hacia una economía de guerra requeria el desplazamiento de recursos economicos hacia fines de guerra, en detrimento de la satisfacción de necesidades populares.

d. La imposibilidad de consolidar una base popular para el modelo reformista (relacionada con el punto anterior).

Las fuerzas sociales y especialmente las bases de apoyo son fundamentales para garantizar la viabilidad de una estrategia económica. De investigaciones recientes se desprende como los efectos de los programas del FMI para las clases sociales de bajos ingresos han tenido generalmente un carácter regresivo en los países de América Latina y de esta manera ponen en peligro la estabilidad de su implementación (véase revisión de Pastor, 1987). Los resultados del presente trabajo confirman esta conclusión y senalan la necesidad de garantizar un minimo de desarrollo del mercado interno como base para cualquier programa de reactivación. Pero igualmente necesario seria asegurarse la viabilidad del modelo por el lado de los sectores productivos, cuya excesiva concentración económica en el caso salvadoreno no dan muchos márgenes de actuación. 


\section{Cuadro 1}

El Salvador: Tasas de creclmlento anuales

(Precios constantes de 1962)

\begin{tabular}{|c|c|c|c|c|c|c|c|c|c|c|}
\hline & $1960-70^{1}$ & $1970-80^{1}$ & 1980 & 1981 & 1982 & 1983 & 1984 & 1985 & 1986 & $1987^{2}$ \\
\hline Producto intemo bruto & 5.0 & 3.0 & -8.7 & -8.3 & -5.6 & 0.8 & 2.3 & 2.0 & 0.6 & 2.6 \\
\hline Agropecuario & 3.6 & 2.7 & -6.6 & -6.4 & -4.7 & -3.2 & 3.3 & -1.1 & -3.1 & 2.5 \\
\hline Mineria & 3.0 & 0.7 & 2.6 & -2.6 & 0.0 & -2.6 & 2.7 & 0.0 & 2.6 & 12.8 \\
\hline Industria manuf. & 7.4 & 2.7 & -16.9 & -10.4 & -8.4 & 2.0 & 1.3 & 3.7 & 2.5 & 3.0 \\
\hline Construcción & 4.2 & 5.2 & -15.1 & -15.3 & -4.2 & 2.0 & -5.7 & 4.6 & 2.6 & 14.0 \\
\hline Electricidad, agua & 9.9 & 8.1 & 4.5 & -3.1 & -2.4 & 5.0 & 2.7 & 5.0 & 2.5 & 2.0 \\
\hline Transporte, etc. & 6.7 & 3.8 & 8.2 & -10.9 & -6.5 & 6.0 & 2.8 & 1.8 & 0.5 & 1.8 \\
\hline Comercio & $5.2^{*}$ & $1.5^{\circ}$ & -12.5 & -14.9 & -12.0 & 2.8 & 1.2 & 0.5 & 0.3 & 2.1 \\
\hline Financiero & & & -8.0 & -9.3 & 5.8 & 0.2 & 1.0 & 3.0 & 1.5 & 2.4 \\
\hline Propiedad vivienda & 3.0 & 3.4 & 3.0 & 2.9 & 2.6 & 2.0 & 1.6 & 1.5 & 0.3 & 1.6 \\
\hline Senvicios personales & 6.4 & 2.0 & -8.9 & -8.6 & -11.5 & -0.5 & -0.6 & 0.2 & 0.5 & 1.5 \\
\hline Administración publica & 4.6 & 5.9 & 3.8 & 1.2 & 3.0 & 1.0 & 6.8 & 7.0 & 4.5 & 2.0 \\
\hline
\end{tabular}

-) Sectores Comercio y Financiero 1 Tasa promedio 2 Preliminar

Fuemb: OIT/PREALC, 198,: 55

MIPLAN, 1987: 16

MIPLAN, 1988: Ap 1, Cdro. 4. 


\section{Cuadro 2}

El Salvador: Evolución principales indicadores macroeconónicos

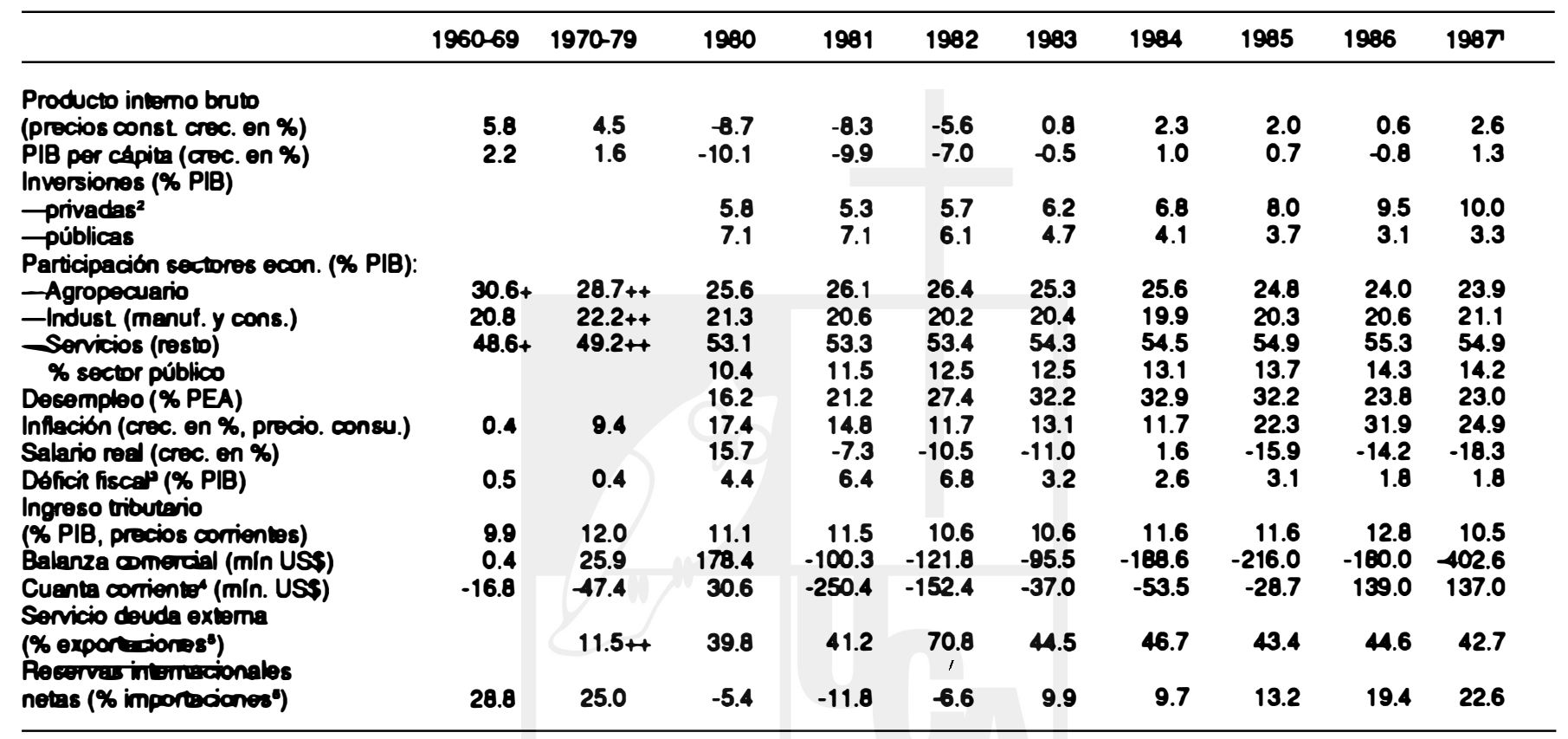

+) $1970++) 1979$

1) preliminar ") incluye vanacion de inventerios ") incluyendo donaciones de AID

4) incluyendo asistencia AID s) bienes y servicios

Fuenios: MIPLAN, 1987; MIPLAN, 1988; IMF, varios; IMF, 1987: 322-325; BCR, 1987: 101; FUSADES, 1987: 10, 12,15; INFORPRESS, 1988; FUSADES, 1986:11. 


\section{Cuadro 3}

\section{Estructura institucional del gasto gubernamental}

(En porcentajes)

\begin{tabular}{|c|c|c|c|c|c|c|c|c|c|c|c|}
\hline & 1977 & 1978 & 1979 & 1980 & 1981 & 1982 & 1983 & 1984 & 1985 & 1986 & $1987^{\circ}$ \\
\hline 1. Defensa y segur. pública & 7.5 & 9.2 & 14.4 & 15.2 & 16.7 & 18.6 & 21.4 & 24.2 & 30.7 & 25.7 & 25.9 \\
\hline 2. Admón. de deuda pública & 3.8 & 4.1 & 4.8 & 5.1 & 10.0 & 15.5 & 14.6 & 26.6 & 13.3 & 19.8 & 17.8 \\
\hline Sub-total & 11.3 & 13.3 & 19.2 & 20,3 & 26.7 & 34.0 & 36.0 & 50.8 & 44.0 & 45.5 & 43.7 \\
\hline 3. Educación & 22.4 & 20.7 & 22.7 & 23.6 & 19.6 & 18.8 & 17.8 & 13.7 & 17.9 & 13.2 & 14.5 \\
\hline 4. Obras públicas & 16.9 & 16.1 & 14.8 & 12.1 & 11.7 & 8.9 & 11.2 & 7.3 & 8.0 & 7.0 & 8.3 \\
\hline 5. Salud pública & 10.2 & 10.7 & 9.8 & 10.5 & 9.1 & 8.2 & 9.2 & 7.0 & 7.5 & 6.2 & 8.3 \\
\hline 6. Agricultura y ganaderia & 8. & 8.2 & 7.7 & 8.2 & 8.2 & 8.4 & 8.6 & 6.7 & 6.7 & 9.7 & 5.1 \\
\hline 7. Transferencias generales & 2.0 & 7.9 & 3.8 & 2.6 & 2.9 & 2.9 & 2.6 & 2.4 & 2.9 & 2.0 & 7.3 \\
\hline 8. Orros & 28.2 & 23.1 & 22.0 & 22.7 & 21.8 & 18.8 & 14.6 & 12.1 & 13.0 & 16.4 & 12.8 \\
\hline TOTAL & 100.0 & 100.0 & 1000 & 100.0 & 1000 & 1000 & 1000 & 1000 & 1000 & 1000 & 1000 \\
\hline
\end{tabular}

-) Cifras preliminares

Fuente: MIPLAN, 1988: Axo 1, Cdro 18. 
1. En los anexos se presentan los cuadros analíticos para todos los años de la década de los 80 y los indicadores promedios para las décadas anteriores a modo de comparación.

2. Calculado con base de datos del FMl: Internacional Financial Statistics, de los años correspondientes.

3. Observación de funcionarios del FMl on (IMF, 1982: 5)

4. Estimaciones del Ministerio de Planificación, publicado en (FUSADES, 1983: 6)

5. Tampoco incluye el personal temporal

6. R. Pigou sobre la economla de guerra, citado en (Instituto de Investigaciones Económicas, 1983)

7. Veáse los resúmenes de los discursos en (CUDI, 1984: 150 y 154)

8. En esta cifra se excluye nuevamente el personal militar, los cuerpos de seguridad y el personal temporal.

9. 1 quintal equivalente a $46 \mathbf{~ k g}$.

\section{Blbllografla}

Banco Central de Reserva (BCR): Indicadores Económicos 1981-1985, San Salvador, 1986a

Banco Central de Reserva (BCR): Memoria 1985, San Salvador, $1986 \mathrm{~b}$.

Banco Central de Reserva (BCR): Revista del Banco Central de Reserva de El Salvador; San Salvador, 1987.

Banco Centroamericano de Integración Económica: La fuga de capital en Centroamérica 1979-1984, Guatemala 1987, Cuaderno No. 1.

Borges, A. C.: Apuntes para balance de los aspectos críticos de la integración oconómica centroamericana; México 1986.

Comentarios: Marcha atrás del 'segundo paquetazo', Revista ECA, San Salvador, marzo 1987.

Report by the comptroller General of US: Providing effective economic assistence to El Salvador and Honduras, A formidable task, Washinton DC. 1985.

CONAPLAN: Plan de Desarrollo Económico y social 1973-1977, San Salvador 1972.

CUDI: EI Salvador, PROCESO, San Salvador 1984.

Declaración Conjunta de 30 gremios empresariales de todos los sectores conómicos, Revista ECA, San Salvador noviembre-diciembre 1986.

Dunkerley, J.: The long war. Dictatorship o Revolution in EI Salvador. Junction Books, London 1982.

FUSADES: La necesidad de un Nuevo Modelo Económico para El Salvador, Lineamientos Generales de una Estrategia; San Salvador 1985.

FUSADES: Análisis crtitico de la polticica fiscal, San Salvador, dic. $1986 b$.

FUSADES: Opciones para financiar el déficit fiscal de 1987, San Salvador, noviembre 1986a 
FUSADES: ¿Como está nuestra economia?, San Salvador, mayo 1987.

Hattield, M. O. et. al.: United States Policy in El Salvador and the urgent need for reform, Washington D.C., noviembre 1987.

IMF: El Salvador, Staff Report for the 1981. Article IV Consultation no sm/82/6, Washington D.C., 8 de abril de 1982.

IMF: International Financial Statistics 1987, Washington 1987.

INFORPRESS Centroamericana, Guatemala, 26 de febrero 1987.

INFORPRESS Centroamericana, Guatemala, 11 de agosto 1988. Instituto de Investigaciones Económicas: Evaluación económica de las reformas, Revista ECA, San Salvador, mayo-junio 1983.

Lichtensztejn S.: De las pollticas de estabilización a las polfiticas de ajuste; Economla de América Latina, México, primer semestre 1984.

Lopez, R.: Los orígenes económicos de la crisis en Centroamérica; Rivera, E., Sojo, A. y Lopez, R.: Centroamérica politica económica y crisis,San José, 1986.

Ministerio de Planificación y Coordinación del Desarrollo Económico y Social (MIPLAN): Plan General de Gobierno 'El Camino Hacia la Paz', parte Económica; San Salvador, 1985.

Ministerio de Planificación y Coordinación del Desarrollo Económico y Social (MIPLAN): Causas de la inflación on El Salvador $\theta$ implicaciones de una nueva devaluación del colón, San Salvador, mayo 1987.

Ministerio de Planificación y Coordinación del Desarrollo Económico y Social (MIPLAN): Programa Económico 1988, San Salvador, enero 1988.

Montes, S.: Clases y movimientos sociales en El Salvador. Caracterización, desarrollo e intervención; Realidad Económico-social, San Salvador, julio-agosto 1988.

OIT-PREALC: Estadísticas e indicadores socio-øconómicos del istmo Centroamericano 1950-1980, geneve 1987.

Orellana S., Pelupessy W., Thielen F.: La productividad y los costos de producción de los cafotaleros en El Salvador, Tilburg, 1986.

Pastor, M.: The effects of IMF programmes in the third world, debate and evidence from Latin America, World Development, no. 2, 1987.

Pelupessy, W.: El Sector Agroexportador de El Salvador. La base económica de una oligarquía no fraccionada, Boletín de Estudios Latinoamericanos, Amsterdam, dic. 1987.

Rosa, H.: Estados Unidos y la crisis centroamericana on los ochenta: La respuesta de la política económica, Universidad Nacional, Heredia, Costa Rica, dic. 1987.

Sánchez, F.: Crisis y politica económica demócrata cristiana, en Revista ECA, San Salvador, julio 1986. 